\title{
DESIGN THINKING TO ENHANCE REQUIREMENTS ANALYSIS IN SYSTEMS ENGINEERING
}

\author{
J. Batista ${ }^{1}$, A. Hassan ${ }^{2, \otimes}$ and E. Bonjour ${ }^{2}$ \\ ${ }^{1}$ Universidade Regional do Cariri, Brazil, ${ }^{2}$ Université de Lorraine, France \\ $\triangle$ alaa.hassan@univ-lorraine.fr
}

\begin{abstract}
Systems engineering (SE) is a general methodological approach that includes all relevant activities to design, develop and verify a system. This work was based on the need to enhance the integration of the customer needs into the design phases of SE. A joint methodology was proposed integrating the SE approach with the Design Thinking (DT). An analysis was conducted as part of a case study proposed by IBM Corporation for the development of a security system for a building. The results confirm that the insertion of the DT in the SE has a significant impact on the generation of concept solutions.
\end{abstract}

Keywords: systems engineering (SE), design thinking, customer integration methods, design process

\section{Introduction}

With the globalization of technology and the increasing of customer demands, markets are increasingly competitive and segmented. Companies compete fiercely to offer quality products at low prices that meet the needs of their users. To do this, it is necessary to develop products that meet the real needs of users and that correspond to their desires (Cesar and Russo, 2018).

Design Thinking (DT) is an approach to innovation that aims to foster strong end-user feedback. This methodology allows the development of products or services that are attractive to the consumer, economically viable, and technologically feasible (Cesar and Russo, 2018; Geissdoerfer et al., 2016). The DT will provide new process models and a set of tools that will impact creative processes in terms of improvement, time reduction, and visualization. This approach helps to analyse user needs and convert this information at the technical level, thus generating specifications for the system (Tschimmel, 2012). The DT assists the involvement of users at the time of decision making in a project (Erzurumlu and Erzurumlu, 2015).

System engineering (SE) has a V-shaped organizational structure for the design process. Its first steps are strongly oriented towards direct contact with stakeholders and collecting their needs to generate the system requirements. On the other hand, it is difficult to integrate these needs into the design process in order to effectively collect impact information for the project. The SysML (System Modeling Language) language diagrams are widely used to establish links between stakeholder requirements and system functions (Hoffmann, 2011).

The work presented in this paper consists of an in-depth study of the ability to integrate the two methodologies (Design Thinking and Systems Engineering) into the process of eliciting and translating the needs expressed by stakeholders. The objective is to obtain more impactful information 
for the design process, and to ensure greater acceptance by potential customers. This work focuses on proposing a method for eliciting and formalizing the needs analysis process deployed in different business areas. To this end, the links between DT and SE areas should be established by promoting their interoperability and complementarity, since they already have a common objective.

An integrated approach is proposed that will be able to effectively integrate different concepts and methodologies to be implemented in design process. It will ensure better analyzing and understanding of needs with stakeholders, which will generate better product acceptance and therefore the success of the design project. To illustrate the proposed approach, a practical case study was carried out in a case of development of a security system proposed by IBM Corporation.

\section{Literature review}

In the process of achieving growth through innovation, Design Thinking is the methodology of greatest concentration and interest, mainly due to the lack of unified standards and models in the development process to achieve success in innovation (Robbins, 2018).

When developing software, it is essential that the development team is able to fully translate and understand the needs exposed by the users, being able to evade the restrictions imposed, such as geographical, budgetary and a restricted project schedule (Cesar and Russo, 2018).

The need expressed in its best form makes it possible to indicate the reason and the moment when one seeks to act. There is a direct agreement with the stakeholders in the process and/or with the client, thus seeking to evolve from the obvious facts presented by them towards formalisation and conformation. This more formalised expression is called stakeholder demand, and brings an evolution of the expressed need, before diffuse and vague (Faisandier, 2013).

Starting by the requirements of the stakeholders, the system requirements are the statements that translates a requirement of the stakeholders (formalized need, expectation, restriction) into technical terms that can be used for architecture and design activities using a semantic code (natural language, mathematical expression, arithmetic, geometric, software language, etc.) (Faisandier, 2013).

By analysing in a general way the development process of a system, the need analysis does not have a clear and objective definition from a theoretical point of view. Compared to the operational vision, its concept is also deficient, companies understand its importance in the product development process, but limit themselves to the idea that the needs analysis is only a set of data on users (Boly et al., 2016). Faisandier (2013) shows that needs are linked to the process and behave in a sequential and complementary way, where the basic level starts with disorganized and unstructured needs, follows the whole process of formalization, structuring, prioritization and choice of needs until they are put into production (Faisandier, 2013).

The success of a project to develop/improve a product/service is directly linked to the successful execution of the needs definition phase. This phase is very important because it is here that the objectives of the project and the means that will be used to meet these needs will be defined (Roby, 2006).

One of the objectives of Design Thinking is the ability to associate the needs of consumers with the product or service that will be developed (Cesar and Russo, 2018).

There are several activities defined by ISO/IEC/IEE 15288:2015 that indicate the sequence of phases and techniques used by system engineering. Activities are logically organized and their application must be associated with an optimal flow with the use of all inputs and outputs provided. Normally, companies are deficient when performing these activities and end up creating discontinuities, i.e. they work to produce outputs that will not necessarily be used in subsequent activities (Faisandier, 2014b). It is important to note that the development of a system does not work in a linear way. To ensure good results and effectiveness, activities must be carried out several times; thus, when there is an information output from one step, in the next step, it will be reanalysed, improved and refined.

The ISO/IEC/IEE 15288:2015 (ISO, 2015) standard gives a sequence of processes related to system engineering. These processes will include specific activities to generate defined results. In this work, the focus will be on the first four processes defined by the standard, which will address the part of understanding project-related concepts, defining needs, transforming them into system requirements, and formalizing and proposing viable solution concepts. 
As there are many activities related to the system development process, they can be grouped together to facilitate their understanding, implementation, and control during the process phases. There are five groups respectively, they will include the basic and support activities associated with the conceptualization and definition phase: Concept definition process, system definition process, technology implementation process and system integration process. The fifth group is the operational life process of the system, which is also part of the life cycle of a system, but its activities are not linked to the development process (Faisandier, 2014b).

For this work, the V cycle (Figure 1) proposed by Faisandier (2013) will be adopted. It is one of the most widely used and most effective models in terms of results (Faisandier, 2013). The V-cycle makes it possible to anticipate and prepare future phases during the top-down stages, where each phase has a corresponding validation test on the opposite side. With this methodology, it makes it easier to review the project and the results of each phase (Faisandier, 2014a).

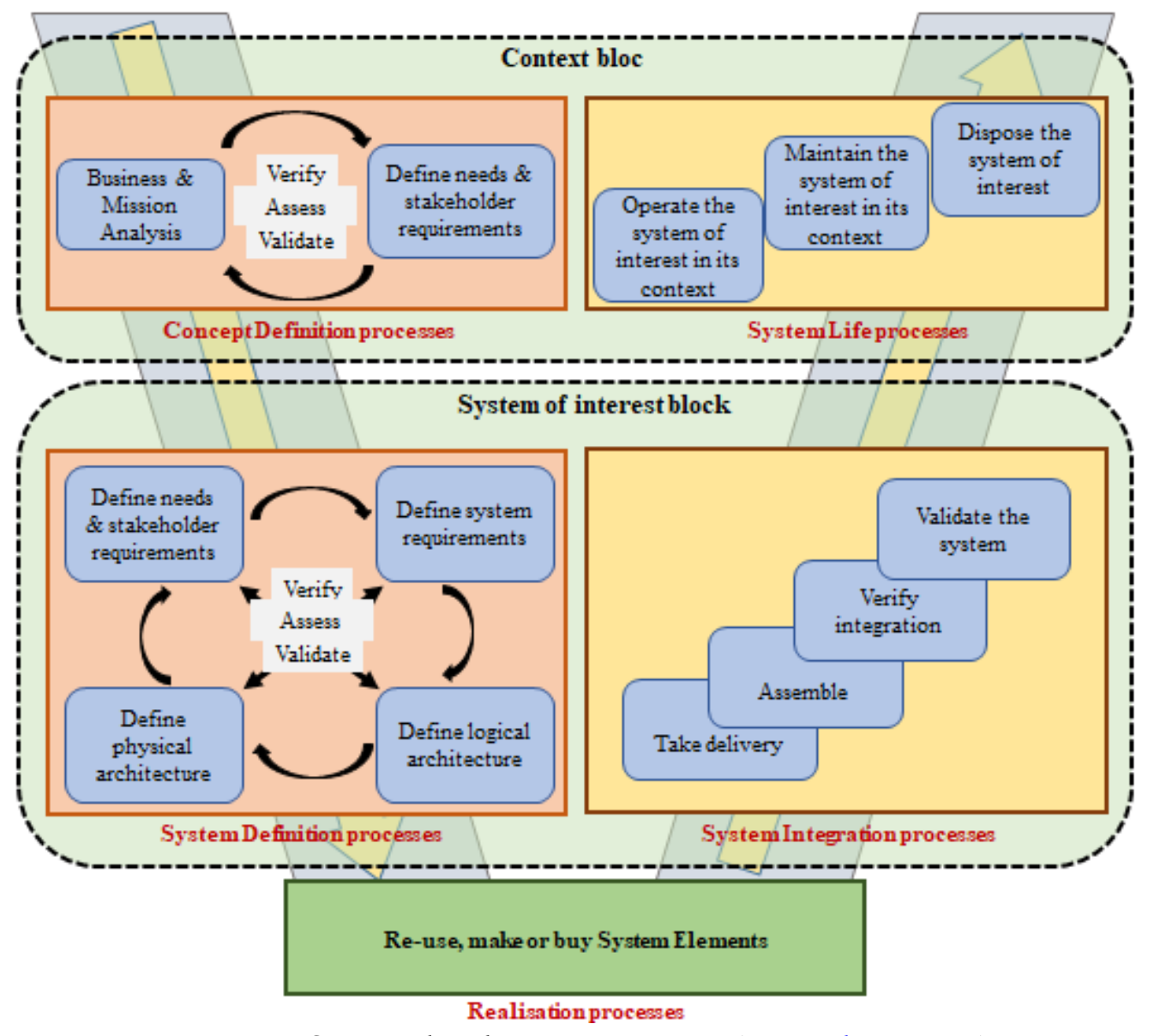

Figure 1. System development processt (Faisandier, 2014)

Many of the problems associated with system design and creation are linked to failures in stakeholder participation in the development process. (Geissdoerfer et al., 2016) Design Thinking is then considered as an effective solution to correct and avoid these failures because of its methodology strongly oriented towards greater user participation, and can be well applied to better achieve the phases of eliciting the real needs of stakeholders, generating more innovative products and services. A major problem for Systems Engineering is to be able to add a more concise methodological orientation for solving problems and finding possible solutions. One possible cause of this problem may then be related to the lack or low participation of stakeholders (Cesar and Russo, 2018).

Design Thinking can be understood as a complex way of expressing new ideas and thoughts, adapting them to emerging needs and cultural and scientific requirements. The new ideas will then be applied to enhance the evolution of innovation (Tschimmel, 2012). In general, Design Thinking will address problems, which are generally difficult to solve using traditional methods, in a more dynamic way, 
stimulating imagination and creativity, and with the aim of generating practical ideas and solutions that have maximum value for the end consumer (Mosely et al., 2018; Lim et al., 2019).

The "user-centred design", is a new approach of Design Thinking that focuses on the innovation in product improvement and design processes. One of the main objectives of Design Thinking is to be able to adopt users perspectives and opinions in the early stages of product design (Mathieu and Hillen, 2016).

This new approach breaks the paradigm that massive investment is needed in quantitative market analysis and new technologies, and seeks greater interaction with users seeking to situate themselves in their environment to understand their problems and needs. With this more realistic understanding of the customer, it is possible to reduce the risks associated with the solutions adopted, identify new opportunities and develop innovations that have a greater impact and add value (Mathieu and Hillen, 2016). The most important point followed by Design Thinking is to successfully promote innovation to users and also to consider the feasibility and viability aspects associated with this solution (Péché et al., 2016).

Several processes and methodologies are used by Design Thinking. The most popular were developed by universities such as Stanford School (Figure 2). These processes are more academic in nature, but can be used with caution by companies in the execution of their projects. This version emphasizes that "you can only see well with the heart", using a first phase of empathy with the user as the first step in the process (Mathieu and Hillen, 2016).

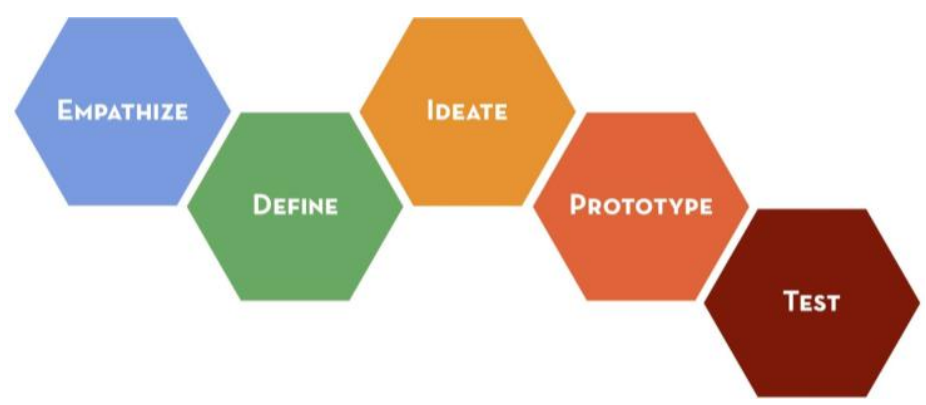

Figure 2. Converging model - Design Thinking process of the Stanford d.school

The methodology used in Design Thinking presents an alternative way to differ from more traditional models in order to act in the search for solutions to organisational problems. Its structure, composed of stages, will allow better control over project execution, controlling the entire process between problem definition phases, solution generation and validation tests (Paula and Cormican, 2016). With regard to Systems Engineering, the Design Thinking will act in a better relationship with stakeholders, providing the necessary resources to carry out the steps of identifying and eliciting needs, and producing prototypes and solutions of innovative dimensions.

After this state of the art, it is possible to conclude that a greater efficiency of both approaches can be guaranteed in the execution of their processes, which will improve and have a direct impact on the expected results. It can be seen that there are gaps in both approaches and that they can complement each other by providing support and improvements with a high impact. In the following section, we will critically analyse examples related to SE processes, highlighting weaknesses or areas that can be improved by inserting the DT and sharing data between these two approaches.

\section{Analysis of complementarity between SE and DT approaches}

The integration of Design Thinking (DT) approach with System Engineering V-cycle is discussed in this section. The focus will be on the early steps of the system development cycle including the definition of the concept and the system definition processes related to the design project. For this purpose, a part of the V-cycle, presented in Figure 1, was considered, observing which weaknesses can be taken into account and completed by the DT methodology (Figure 3).

The main contribution of the DT in SE is associated with the empathy phase (E), where there is a deficiency in the current SE methodology, which does not have an adequate and centralized structure for more expressive contact with project stakeholders. In addition, another contribution of the DT associated with the SE is the development of prototypes $(\mathrm{P})$ and testing $(\mathrm{T})$ of solutions with stakeholders. In the SE model, there is an association of architecture design only with the team of developers, leaving aside the 
main actors of the project who are the customers. In our proposed model, the DT acts as a bridge between these two spheres and promotes interaction during the development of the architecture, from the construction of prototypes to the validation and the feedback of the stakeholders.

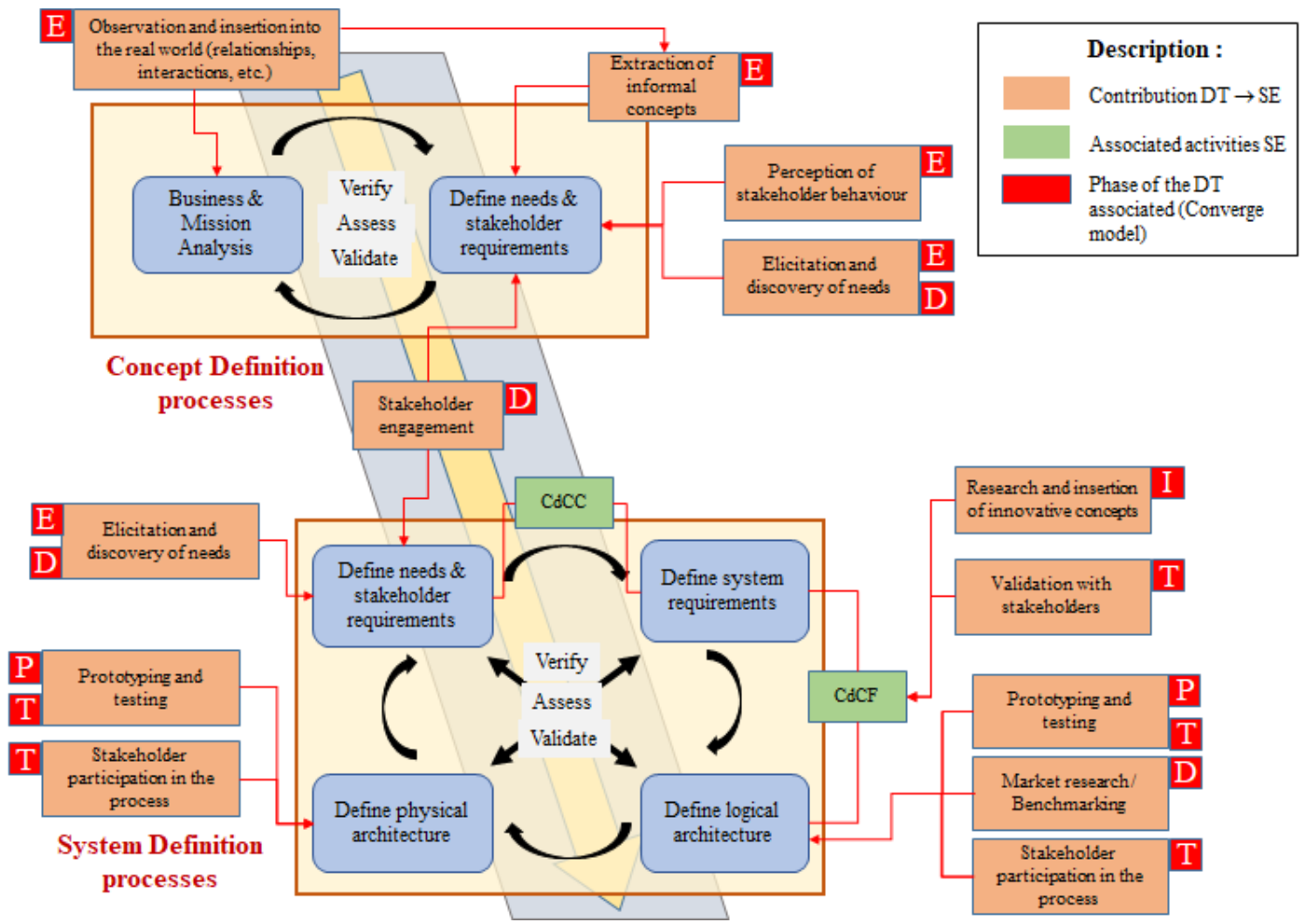

Figure 3. Proposition de complémentarité DT $\rightarrow$ SE

The DT has a better methodology of direct empathy (E) with the client, which facilitates the observation of the client's direct relationships with his environment, which can contribute to and influence the concept of the solution. The DT is then an ideal approach to dealing directly with stakeholders, highlighting their needs and influences resulting from various factors, and therefore it can contribute to the SE by providing a first entry of concepts even if not yet formalized but which can now be addressed and worked on solutions that will have more impact for the client.

The SE is already well structured in terms of formalising and documenting development activities. There is already in its process the preparation of formal documents such as the CdCC (Customer Specification) and the CdCF (Functional Specification), which facilitate project management and the entire execution process. In the phase of the system definition process, the principal need presented by the SE concerning the DT is to be able to include, in its definition of system solutions, concepts that are more innovative for the market and that ensure a better performance of the system solution and therefore a better acceptance by the customer. As the SE has a methodology that is internal to its process, it is necessary to integrate the DT methodology in order to search for more innovative concepts for the project and which guarantee a greater attractiveness and acceptance of the solution.

Before the production process, it is proposed to implement the DT within the SE in relation to the formalization of prototypes and the carrying out of validation tests with the project clients. In the current SE methodology, this stakeholder validation process does not necessarily take place in this phase, which can lead to disagreements with clients about the proposed solution. It is therefore important to validate with them what is defined as a solution concept, to ensure that their needs have been well understood and that what is proposed meets their expectations.

\section{Case study: IBM Corporation security system}

This section illustrates the proposed approach via a case study presented in the Deskbook used by IBM Corporation to complete the Rational Rhapsody training (Hoffmann, 2011). The example chosen 
concerns the development of a security system for a building. This building is held by a company that has expressed the need to improve its system for controlling the entry and exit of people. Its needs to ensure the security of the equipment located there, its personal data and information, and its employees in their work environment.

This case study is organized and detailed by a Deskbook distributed by IBM, covering all phases of the model-based system engineering process (SysML). It explains the execution of the requirements analysis, functional analysis of the system and project synthesis steps, as well as the management and traceability of the associated requirements. Rhapsody's workflow begins with importing stakeholder requirements and ends with defining an executable architecture model.

The first phase begins with the import and receipt of requirements defined by the stakeholders of the security project. These requirements were first expressed in the form of needs and then translated and formalized in a more technical way, in order to facilitate the engineering work and the inclusion of this information in the result.

From the first phase of the development process of a security system through system engineering, the initial information is the technical requirements of the stakeholders. By using the SE-Toolkit tool, it is not possible to work directly with the definition of stakeholders' needs (activity preceding the formalization of requirements). This shows us that there is a gap between system engineering and stakeholders with regard to pre-project activities, when the SE cannot and does not have sufficient support to establish this link. Inserting the Design Thinking methodology to identify the stakeholder needs can create this link. DT offers an empathic dialogue with stakeholders in order to observe their needs, formalize them and analyse the real conditions in which the client need is taken into account and which can influence the realization of the product.

The SE identified three different use cases in this project (Figure 4): Control of employee entry, control exit and configure security system. For actors are also determined: Employee, Administrator, Camera and Access Point.

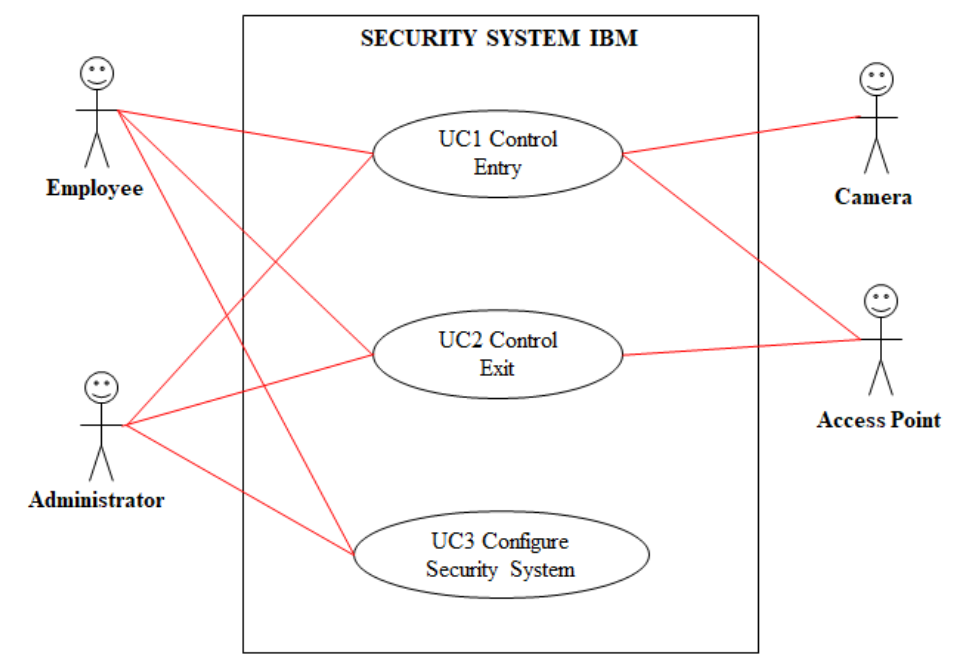

Figure 4. Use case diagram of the IBM security system (Hoffmann, 2011)

In the second phase of the project, a functional analysis of the system was carried out. This analysis is highly based on the use cases that were defined in the previous step. Basically, these use cases are translated into executable models for the system. The model and related requirements are then verified by the model execution.

So far, it can be seen that there is no validation activity at any time with the client regarding the functions that have been defined at the end to integrate the security system that will be developed. Thus, the DT could propose a validation activity for these functions to ensure customer satisfaction, and prove that the idea of need initially expressed was well understood and structured in the form of a solution concept.

The third phase is the architectural analysis phase; it aims to determine a more effective solution to meet the necessary functionalities identified in the previous phase of functional analysis of the system. 
In the original study, after a comparative analysis of the possible solutions, it was concluded that the architecture of the fingerprint scanner would be the most efficient for the defined criteria and therefore the most suitable for the project. This result is explained mainly by the high costs associated with the acquisition and installation of the optical scanner architecture (second proposal raised).

It is also noted that when solution concepts are selected, thee user did not participate to any performance evaluation of the security system. It could be added, for example, "Technical capacity of the customer" criteria. In this criterion, the users' behaviour towards these technologies could be observed as well as their understanding and their potential use. This criterion could be decisive if the technology was highly complex for the client use, which would require intensive training, or even more rigorous monitoring during use. This analysis, if not performed, could cause problems such as errors in use, not using the product, inability to use it, etc.

With regard to the development of these first three steps, DT tools are used to analyse possible changes in this scenario that has been defined by the SE. As a starting point, a journey mapping (Table 1) was developed to observe how this system would work in practice and what are the observations and effects identified by users associated with this system.

The journey mapping refers to all the actions and interactions that a customer will have with a company/product during the process of purchasing or using a product or service. Its process corresponds to a path of use and interaction, where the points of exchange between the product and the user will be evaluated, detailing their satisfaction / difficulty of interaction with the product. From this information, points of improvement resulting from the use process can be observed and reviewed to participate in the design project.

An analysis was performed for an associate employee. There is a certain degree of dissatisfaction from some clients with the use of the system. Problems have been observed in the execution process, which, due to their individual nature and the need for certain validation steps, cause failures and delays for the user who executes them. This results in a long queue that causes employee dissatisfaction and delays in the process. To solve this problem, we have proposed the association of a new actor to the system, here called a facilitator, who will help those employees who have difficulty in performing their validation. This should speed up the process and end or reduce the queues. Figure 5 represents the new use case diagram developed after the journey map analysis with the integration of DT. The new facilitator actor was added to the use case diagram; this actor has not been identified by the SE team in the original analysis. Changes made from the DT are highlighted in purple.

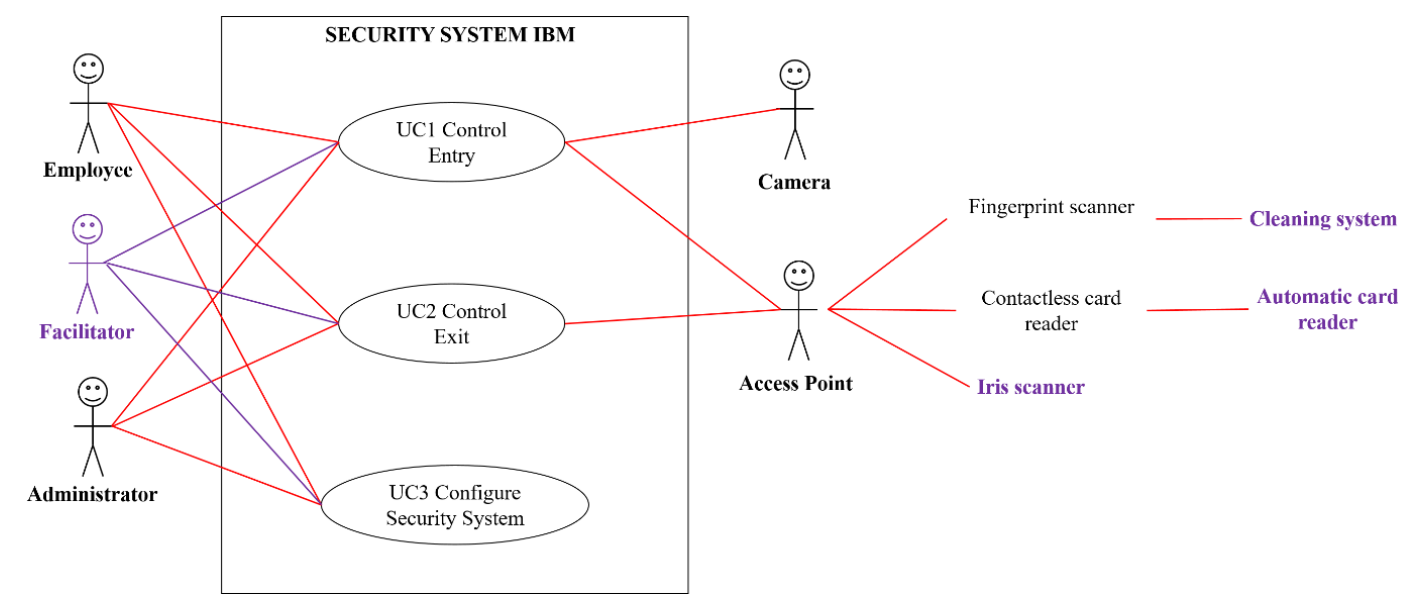

Figure 5. Modified use case diagram of the IBM security system after DT integration

The journey mapping allowed us to observe new trends and needs expressed by the employees who use the security system proposed by SE. There are problems that were not observed in the initial analysis conducted by SE team. The first problem is the use of the security card for validating information. In the company, it is common for employees to move around with boxes and equipment in their hands, making it difficult for them to find the card in their handbag or pocket to execute the validation process. One solution proposed is the use of an automatic card reader, which allows 
employees' data to be read and validated only in their presence, without requiring direct interaction with them (contactless reading).

Table 1. Journey mapping of the IBM security system user

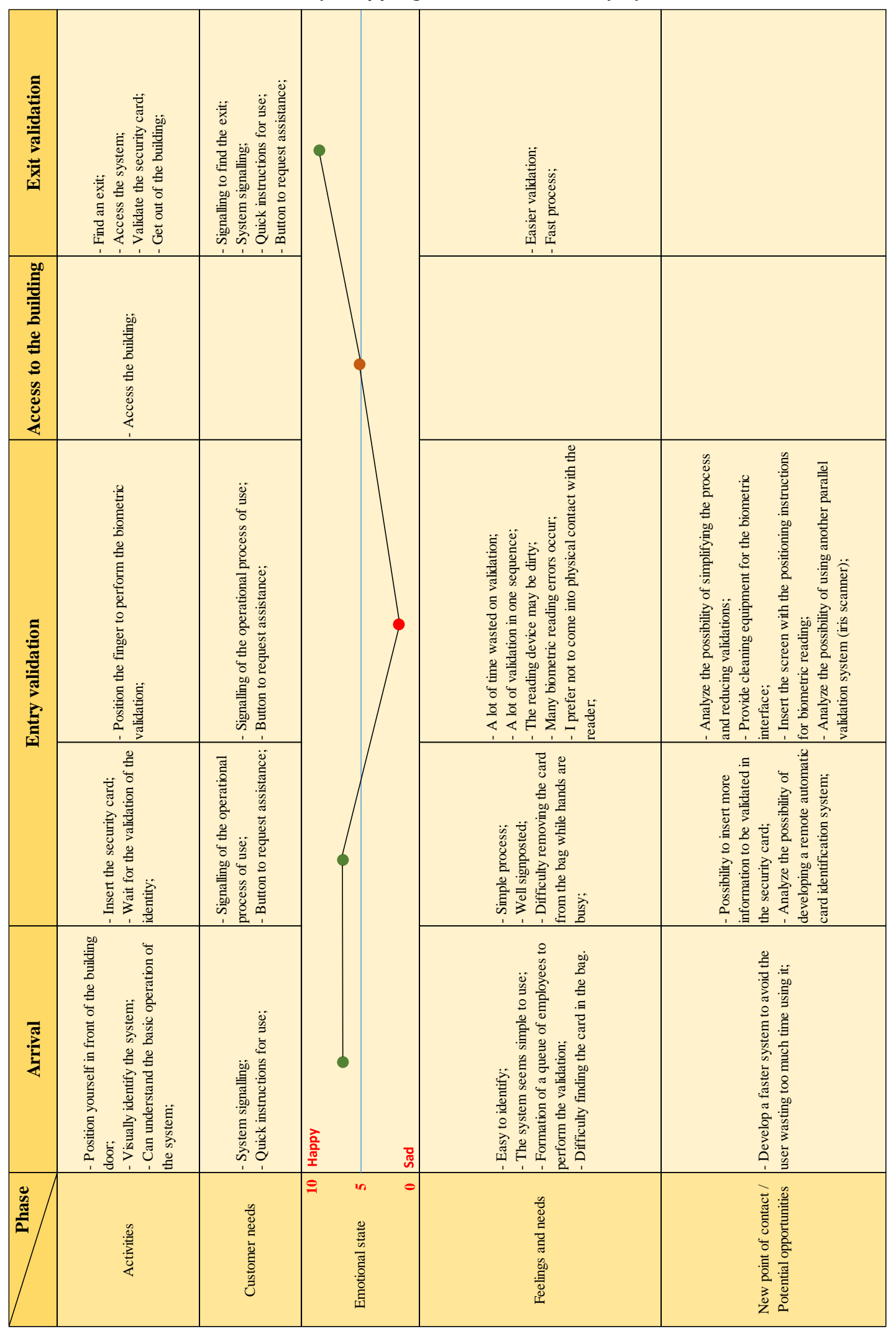


Another problem observed was the biometric scanner. Some employees, for hygienic reasons, may prefer not to contact the reading device directly, due to the large number of users who use it every day, which makes it contaminated and dirty. A solution for this case would be the implementation of a cleaning system, through the availability of a hypoalcoholic hand gel or wipes for the scanner, that would help the employee to clean the contact area and make better use of the system. As a result, there was also a difficulty in biometric reading, probably due to impurities in the employee's fingers or in the sensor itself, so the proposed cleaning system can also increase the employee satisfaction.

In addition to this biometric reading system, another system could also be implemented, such as the iris reading system, for example, which would avoid direct contact with the employee and improve the process, in this way, even with a dirty and busy hand, he could choose not to use the biometric reader and perform the validation via the iris reader. This can improve system performance and optimize customer uptime, thus improving customer satisfaction.

In DT methodology, the solution concepts are evaluated and tested with the customer in prototyping and testing phases. Prototypes will be developed for each solution of the system and will be tested with the associated users. In this way, new requirements and modifications could be found and added to the initial solution, such as improved ergonomics, structure, performance, creation of new interfaces, etc. The information observed here must be processed and integrated into the solution concept so that production orders can then be sent to the responsible workshops or suppliers. This analysis will have a direct impact on the efficiency of the system and therefore on customer satisfaction when using it. Figure 6 shows the impact of prototyping and testing phases after the integration of DT. The concepts and proposals made during DT methodology are prototyped and tested with the costumer before their validation. Changes made from the DT are highlighted in purple.

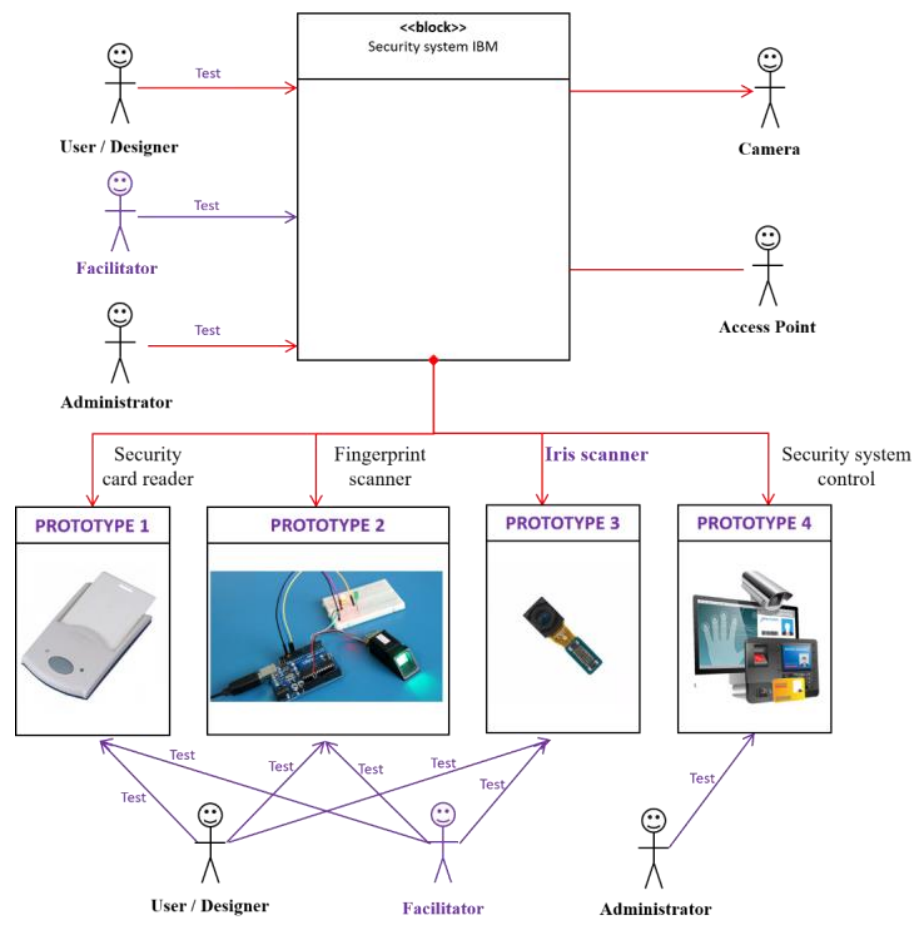

Figure 6. Testing different prototypes before solution validation

In this proposed approach, the DT motivates the participation of the actors in order to test the solutions. To perform the test, prototypes are developed, which will facilitate the actor to analyse the experience of using what is being proposed, and identify the necessary improvements and adjustments.

\section{Conclusions}

This research work is based on the observation of the need to improve the System Engineering approach in order to be able to more effectively integrate the stakeholders involved in the project into system design process. In SE process, the stakeholder involvement has not been clearly structured or 
tooled. It was necessary to integrate them better from the preliminary project phases, starting from the definition of concepts and the information collection, to the production phases, the validation of proposed solutions and the external commercial feasibility study of the project. The DT approach is a very good candidate that places the customer at the center of the development process. It was deployed in SE process as a supporting methodology to help correcting this deficiency.

In the case study on security system development project of the IBM Corporation, it was found that the methodologies related to the SE approach lack of analysis tools with project stakeholders. After the application of the DT tools, such as journey mapping, new needs and factors important to the project from a client perspective were observed that were not previously identified when it was limited to using only the SE.

\section{Acknowledgement}

The authors would like to thank the ERPI laboratory (Research team on innovation process) and the ENSGSI (École Nationale Supérieure en Génie des Systèmes et de l'innovation) - Université de Lorraine, for their collaboration and participation in the realization of the case study and the presented research work.

\section{References}

Boly, V. et al. (2016), "From descriptive customer data to need definition: a formalised approach", International Journal of Product Development, Vol. 21 No. 5/6, p. 369. https://doi.org/10.1504/ijpd.2016.10004476

Cesar, J. and Russo, R.D.F.S.M. (2018), "Design Thinking Integrated in Agile Software Development: A Systematic Literature Review”, Procedia Computer Science, Elsevier B.V., Vol. 00 No. 138, pp. 775-782. https://doi.org/10.1016/j.procs.2018.10.101

Erzurumlu, S.S. and Erzurumlu, Y.O. (2015), "Sustainable mining development with community using design thinking and multi-criteria decision analysis", Resources Policy, Elsevier, Vol. 46, pp. 6-14. https://doi.org/ 10.1016/j.resourpol.2014.10.001

Faisandier, A. (2013), Systems opportunities and requirements, Sinergy'Com, France.

Faisandier, A. (2014a), "Ingénierie des besoins et des exigences d'un système complexe," Innovation | Management et ingénierie de l'innovation, pp. 1-6.

Faisandier, A. (2014b), Notions de Système et d'ingénierie de système, 1st ed, Synergi'Com, France.

Geissdoerfer, M., Bocken, N.M.P. and Jan, E. (2016) "Design thinking to enhance the sustainable business modelling process - A workshop based on a value mapping process," Journal of Cleaner Production, Elsevier Ltd, Vol. 43, pp. 1218-1232. https://doi.org/10.1016/j.jclepro.2016.07.020

Hoffmann, H.-P. (2011) Systems Engineering Best Practices with the Rational Solution for Systems and Software Engineering Deskbook, 2nd ed. https://doi.org/10.1109/MS.2009.80

ISO (2015), Systems and software engineering - System life cycle processes, 1st ed. Edited by I. I. 15288. ISO/IEC/IEEE 15288

Lim, C. et al. (2019) "Multi-factor service design: identification and consideration of multiple factors of the service in its design process," Service Business, Springer Berlin Heidelberg, Vol. 13 No. 1, pp. 51-74. https://doi.org/10.1007/s11628-018-0363-z

Mathieu, F. and Hillen, V. (2016), Le Design Thinking par la pratique: De la rencontre avec l'utilisateur à la commercialisation d'un produit innovant pour les seniors, Eyrolles, Eyrolles, Paris.

Mosely, G., Wright, N. and Wrigley, C. (2018) "Facilitating design thinking: A comparison of design expertise," Thinking Skills and Creativity, Elsevier, Vol. 27 No. January, pp. 177-189. https://doi.org/10.1016/ j.tsc.2018.02.004

Paula, D. and Cormican, K. (2016) "Understanding Design Thinking in Design Studies (2006-2015): A Systematic Mapping Study," In 14th International Design Conference, pp. 1-10.

Péché, J.-P., Mieyeville, F. and Gaultier, R. (2016) "Design thinking: le design en tant que management de projet," Entreprendre \& Innover, Vol. 28 No. 1, p. 83. https://doi.org/10.3917/entin.028.0083

Robbins, P. (2018) "From Design Thinking to Art Thinking with an Open Innovation Perspective — From Design Thinking to Art Thinking with an Open Innovation Perspective - A Case Study of How Art Thinking Rescued a Cultural Institution in Dublin," Journal of Open Innovation: Technology, Market, and Complexity, Vol. 57 No. April 2017. https://doi.org/10.3390/joitmc4040057

Roby, T. (2006), Maîtrise d'Ouvrage - Maîtrise d'Oeuvre: Dans le projets de mise en oeuvre de Systèmes d'Information.

Tschimmel, K. (2012) "Design Thinking as an effective Toolkit for Innovation," In The XXIII ISPIM Conference, pp. 1-20. 